\title{
As Origens e O IMPACTO EdUCACIONAL DA Fundação Carlos Chagas
}

\begin{abstract}
ISAIAS RAW ${ }^{1}$
Na recém-comemoração dos 35 anos da Fundação, foram relembrados alguns pontos da nossa história. Como cada ex-Presidentes, outros Diretores e seus principais funcionários, com quem repartimos a aventura, tinham funções e interesses especiais, faltou uma visão mais abrangente da origem e principalmente do impacto desta.

Leser $^{2}$, à testa do vestibular da Escola Paulista de Medicina, foi definitivamente o pioneiro. Ele introduziu os métodos que permitiram transformar o vestibular numa seleção objetiva, pelo uso dos testes de escolha múltipla. Ao contrário do que ainda se assume, a chance de escolher uma das cinco possibilidades não favorece àquele que ignora a resposta certa. Um candidato que consegue eliminar duas das cinco respostas tem definitivamente uma chance maior do que aquele que, não conhecendo o assunto, tem apenas uma chance em cinco de acertar. O uso desta prerrogativa, nos testes de escolha múltipla, foi e é um processo educacional, pois estes estudantes, como futuros profissionais, passarão o resto da sua vida usando o que conhecem para melhor encontrar um resposta que desconhecem.
\end{abstract}

1 Professor Aposentado da Faculdade de Medicina da Universidade de São Paulo. Ex-Diretor do Instituto Butantã. Ex-Presidente da Fundação Carlos Chagas (1967-69).

$2 \mathrm{O}$ autor refere-se ao Prof. Dr. Walter Sidney Pereira Leser, Professor Aposentado da Antiga Faculdade Paulista de Medicina, hoje Universidade Federal de São Paulo, e idealizador da Fundação Carlos Chagas. 
Com os testes de escolha múltipla, Leser introduziu a técnica estatística para a sua análise, podendo assim selecionar os testes que melhor discriminam entre os primeiros e os último colocados. A criação de um banco de bons testes discriminativos, como faz o Board of Medicine no Estados Unidos, permite, além de reutilizar os testes mais discriminativos, acumular experiência para preparar novos testes, treinando os examinadores.

Outro ponto introduzido por Leser foi um teste de aptidão intelectual. Este teste permite, com alguma precisão, contribuir para escolha de candidatos mais capazes. Este tipo de teste foi abandonado em sociedades com muitos grupos étnicos, como a dos Estados Unidos, pois a escolha do vocabulário tende a privilegiar as classes mais abastadas. Este problema existia entre nós, mas a diferença vem claramente diminuindo no Brasil de hoje, com a televisão que é comum a todos as classes e regiões.

Leser também teve uma importante contribuição na concepção das provas de inglês e português. Usando testes de escolha múltipla foi possivel testar a compreensão ao invés de saber se os candidatos leram sinopses dos livros de Machado de Assis ou quando Milton escreveu o Paraíso Perdido, o que pode ser interessante, mas nada tem com a meta de selecionar os que, tendo capacidade de aprender, poderão retornar o investimento que a Sociedade fez ao dar-lhes um cursos superior de alto nível. O mesmo ocorreu na prova de História, para uma juventude que compacta César, Napoleão e até Hitler como passado remoto e irrelevante para a vida contemporânea. Introduzimos os importantes eventos do anos recentes, levando os jovens a repartir o seu tempo entre o preparo para os vestibulares com a leitura séria dos jornais, substituindo a prova de história por conhecimentos gerais.

Ao oferecer uma alternativa para as dissertações, os testes tornaram possível a comparação de candidatos, 
em número crescente, com uma precisão na apuração absolutamente impossivel por provas escritas. Esta afirmação, que é de um óbvio ululante, foi estatisticamente comprovada por um teste que Leser realizou na Escola Paulista de Medicina. Por outro lado, uma avaliação imprecisa de provas constitui, ao alocar um candidato a uma escola paga ou pública, na Capital ou no Interior, uma injustiça.

A etapa seguinte foi a criação de um vestibular para mais de uma escola médica, terminando com a tourada de múltiplos vestibulares paralelos (cinco, na época), onde além do desgaste emocional de cada candidato, a resposta sempre aguardava que eles, candidatos, que foram classificados em mais de uma Escola, decidissem qual iriam cursar, liberando as vagas para outros. Nesta época, o prestigio maior era (pela escolha dos próprios candidatos) a Faculdade de Medicina da USP. Eu havia assumido o vestibular. Ao sair da sala da Congregação encontrei Leser no corredor e discutimos pela primeira vez o que parecia impossivel: combinar os vestibulares da Medicina USP com a Paulista. Cada um de nós foi obter autorização e o processo foi tão aceito, que nos aventuramos em convidar as demais escolas médicas do Estado num total de cinco.

Combinado a criação do chamado $\mathrm{CESCEM}^{3}$, que se instalou na Faculdade de Medicina da USP, o problema seguinte era como financiar o vestibular. Instituimos uma taxa para o vestibulando, que seria recolhida no momento da inscrição. Como precisávamos dos recursos para preparar o vestibular, a inscrição foi antecipada para Julho. No ano zero, os vestibulares continuaram separados e a taxas formaram um fundo. O volume de dinheiro recolhido era tão grande que uma das Faculdades reteve as taxas e desistiu do exame unificado.

3 CESCEM - Centro de Seleção para as Escolas de Medicina. 
O vestibular como fonte de renda de escolas superiores havia sido inventado.

Já no ano seguinte, os candidatos pagaram no BANESPA, inaugurando outra idéia que passou a ser adotada, onde o Banco prestava este serviço, acessivel em todos os bairros e nas cidades do Interior. O uso do Banco, hoje usual, foi uma inovação numa época onde eles não prestavam serviços deste tipo. Com o preenchimento de um formulário simples, aqueles que não podiam pagar tiveram a taxa dispensada.

A tarefa que assumimos era, para a época, enorme. O primeiro vestibular usou um formulário para a resposta. Adolfo Lerner (hoje no INCOR $^{4}$ ) tentou desenvolver, em algumas semanas, um leitor ópticoeletrônico (que sonhávamos seria usado para tornar a apuração rápida e sem possivel corrupção das eleições, o que só aconteceu recentemente). Não conseguimos a tempo e tivemos que usar máscaras para rapidamente computar os pontos.

Faltava não apenas a correção automática, mas a computação das notas e classificação dos candidatos, que foram lotados de acordo com os pontos conseguidos, atendendo a seqüência de suas preferências. Foi quando mobilizamos Setzer ${ }^{5}$ e Isu ${ }^{6}$ do Centro de Computação da USP. Substituímos a correção de máscaras pela máquina mark-sense, do escritório central da IBM, varando a noite para corrigir alguns milhares de provas, checando quando as marcas incompletamente feitas não eram lidas. Os resultados foram transferidos por digitação para outras fichas e introduzidas no "enorme" computador da USP (menor do que um PC moderno), que elaborava as listas dos pontos obtidos pelos candidatos, levando em conta os pesos diferentes para cada prova.

${ }^{4}$ INCOR - Instituto do Coração.

5 O Autor refere-se ao Prof. Dr. Waldemar Setzer, Professor Aposentado do Instituto de Matemática e Estatística da USP.

6 O Autor refere-se ao Dr. Isu Fang, na época, do Centro de Computação da USP; hoje, da Fang e Ripper Engenharia Consultores. 
À experiência de Leser com as provas objetivas juntou-se a operacionalização computacional de Isu e Setzer, numa época onde os computadores eram primitivos, raros e os programas inexistentes. Alimentado todas as respostas a cada pergunta, foi possivel operacionalizar analise dos testes.

O impacto dos exames do CESCEM foi fantástico. A utilização do computador para correção e classificação trouxe uma enorme credibilidade. Acabaram os pedidos de professores, autoridades e outros poderosos: o computador não tinha ouvidos... Havíamos moralizado definitivamente o vestibular.

Para avaliar a credibilidade deste vestibular, basta lembrar o que ocorreu, creio, no terceiro ano. O filho de um médico do Hospital das Clínicas demonstrou que sua classificação não estava correta. No primeiro momento, fiz ver que computadores não erravam, mas em deferência à posição firme do jovem, comprometi-me a, manualmente, verificar os resultados. Para minha completa surpresa, não condiziam com a classificação! Setzer e Isu pesquisaram e descobriram que, no momento de introduzir a nota de cada prova, houve uma inversão. Como conseqüência, os pontos foram multiplicados pelos coeficientes trocados. Lembro-me da longa discussão que se seguiu: todos os candidatos haviam sido tratados da mesma forma. Poderiamos deixar os resultados como estavam, pois seria improvável que alguém descobrisse o erro, mas depois de ponderar que poderíamos estar vivendo o fim do CESCEM, recalculamos tudo. A classificação mudou muito. Chamei a imprensa e anunciamos nova lista. Alguns classificados para a segunda fase do vestibular foram eliminados, mas não houve nenhuma contestação e o CESCEM continuou a merecer a confiabilidade da Sociedade.

O ovo estava de pé e novos grupos de vestibulares se formaram, alguns com nosso apoio técnico (como o vestibular à Faculdade de Medicina da Universidade do 
Brasil), outros simplesmente reconstruindo o que tínhamos introduzido, o que foi o caso das Engenharias (MAPOFEI) e das economias (CESCEA) ${ }^{7}$.

Havia, entretanto, uma diferença fundamental entre o CESCEM e outras iniciativas. O CESCEM converteu-se numa Fundação, que empregaria os recursos não apenas para pagar os custos do vestibular, mas para realizar pesquisas, imprimir os primeiros guias que explicavam aos candidatos o que eles poderiam esperar não apenas na vida profissional, mas nos 4-6 anos enquanto estavam cursando e novas iniciativas. Os professores contratados para preparar os testes, poucos funcionários e fiscais eram pagos. Os diretores, como reza a lei das Fundações, nada recebiam. Evitamos transformar o vestibular num negócio.

As provas de escolha múltipla e a computação tornaram o vestibular viável e exato, preparado para enfrentar, dispondo de computadores adequados, qualquer número de candidatos. Foi quando passamos a aceitar outras Escolas Superiores, como a Faculdade de Medicina do Paraná e as Faculdades de Odontologia, Farmácia e Veterinária. Esta ampliação trouxe problemas que tiveram de ser corrigidos. Como os alunos podiam priorizar todas as escolas e cursos oferecidos, a Faculdade de Medicina do Paraná recebeu praticamente só paulistas, que sabíamos voltariam a São Paulo por transferência, quando havia vagas, ou depois de formados, privando este Estado de médicos. Os alunos, que tendo pontos mais baixos entraram na veterinária, voltaram no ano seguinte para novo vestibular e quando conseguiam entrar na medicina, abandonavam a veterinária que ficou com vagas não preenchidas. Passamos a restringir a escolha apenas para um Estado (e mais tarde dando assistência ao Paraná e a

\footnotetext{
$7 \mathrm{O}$ autor refere-se a instituições surgidas após o CESCEM e que passaram a fazer os vestibulares de exatas (MAPOFEI) e de humanidades, economia e administração (CESCEA).
} 
Pernambuco para realizar seu vestibular) e no caso de várias opções profissionais, dar preferencia aos alunos que escolheram estas profissões.

Este breve relato esclarece como surgiu a técnica do vestibular em larga escala. Não menos importante foram a introdução de medidas de segurança com o preparo, impressão, distribuição e coleta das provas. Montamos uma tipografia em um salão, de endereço não divulgado, no interior de um imenso cofre. Os pacotes com selos de inviolabilidade eram transportados pelos Diretores e seus carros seguidos por policiais.

Preenchemos as vagas disponiveis com os candidatos mais credenciados a ter um bom desempenho tanto no curso superior como profissional, garantindo assim o investimento público (no caso da Faculdades públicas). Todavia, esta técnica que tornou o vestibular preciso e seguro não era a única meta. Certamente não era a minha.

A Faculdade de Medicina da USP hospedava outra atividade educacional, nascida treze anos antes do Cescem, que tinha como objetivo a melhoria do ensino da ciências na escola média. O vestibular oferecia uma oportunidade especial para ajudar a introduzir as inovações do ensino. Assim, o Cescem surgiu desde o primeiro dia como uma irmão gêmeo do então IBECC São Paulo (Instituto Brasileiro para Educação, Ciência e Cultura), que estava inovando o conteúdo e a filosofia do ensino das ciências.

Num programa que iniciamos em 1952, começamos a introduzir mudanças fundamentais no ensino médio de ciência. Um dos pontos fundamentais era substituir informação pelo conhecimento de como opera a ciência e os cientistas, o que James Connant (Professor da Harvard que se tornou o chefe do Plano Marshal), chamou de táticas e estratégias da ciência. Ao aprendêlas, imaginávamos que o estudante pudesse aplicar o que aprendeu na vida real e, sobretudo, ser 
racionalmente capaz de julgar evidências que se apresentam, livrando-se da falsa propaganda e outras formas de como o cidadão, escolarizado ou não, é constantemente enganado. Para aprender e entender ciência não bastava ser capaz de conhecer o jargão, memorizando informações (que lhe garantem até hoje bons resultados nos vestibulares e nos provões), mas vivenciar como se faz ciência, colhendo dados de experimentos reais, tirando conclusões provisórias, para projetar novas experiência que comprovam ou modificam suas conclusões. Era preciso, portanto, usar as mãos com a cabeça. O clássico laboratório de ciências era constituído por equipamentos caros, cromados e inúteis, construídos para não funcionar, mas só para mostrar ou para dar sempre os mesmos resultados. O IBECC passou, ao lado de onde mais tarde se instalou o CESCEM, a produzir kits simples, imaginativos, que chegaram aos alunos e destes para as escolas.

Foi, então, introduzido no vestibular, para cerca dos $10 \%$ dos alunos melhor classificados, um exame de laboratório, onde os estudantes faziam algumas experiências de química, física e biologia, dando resposta em forma de múltipla escolha, facilmente avaliada com rigor. 1.200 alunos, no mesmo dia, enchiam os laboratórios do Instituto de Química da USP para realizar estas experiências. Para isto ser possivel, o IBECC, em sigilo, produzia uma centena de conjuntos de materiais. 
EXAMES PRÁTICOS DO CESCEM

(Fotos da coleção de Isaías Raw) 
Esta é ainda a maior operação que já houve deste tipo, aferindo a competência de enfrentar, na realidade, um problema e aplicar o que haviam estudado. Assim, os $10 \%$ dos melhores alunos, que resolviam no papel "problemas" de circuitos com leis de Ohms e Kirchoff, revelaram que na maioria eram incapazes de ligar um voltímetro nos terminais de baterias (escondidas numa caixa), descobrindo como estavam ligadas. Vi uma centena de candidatos, que ligaram apenas um fio no voltímetro, esperar por mais de 5 minutos que ele apontasse a tensão. Se fossem perguntados, como o foram na prova, qual a velocidade da eletricidade, diriam 300.0000 quilômetros por segundo (errado).... mas 
esperavam que levasse minutos para percorrer alguns centimetros.

Num ano, suspeitamos que houve espionagem no IBECC e que haviam descoberto o que seria experiência de física. Teixeira ${ }^{8}$ (que dirigiu o FUNBEC) mandou comprar alguns milhares de fichas de cartão e réguas. Os alunos tinham que medir o volume de uma ficha e a maioria tentou medir a espessura da ficha com a régua, ao invés de medir a espessura de 10 ou 20 fichas e calcular a espessura de uma.

Este exame de laboratório levou as escolas (e até os cursinhos) a introduzirem no currículo as experiências feitas pelos alunos, criando o clima que levou mais tarde o IBECC e a Abril9 a se associarem para produzir 3 milhões de kits (OS CIENTISTAS), que se tornou a maior escola sem escola, sem "decoreba" e sem repetições encenadas na televisão.

Nesta época, o IBECC havia se tornado um líder na inovação do ensino das ciências, conhecido e reconhecido principalmente através da UNESCO e da União Pan Americana. A inovação deveria atingir primeiro o livro usado e só poderia ser feito pela liderança de cientistas de alto nivel que acompanhavam o avanço da ciência e seriam capazes de julgar o que era importante e o que era tradicional e inútil. Descobri que a mesma idéia surgiu nos Estados Unidos, quando Zacharias, Professor do MIT ${ }^{10}$, iniciou a renovação do ensino da física que rapidamente se estendeu para o resto das ciências. Zacharias tinha um IBECC (onde passei algum tempo quando me exilaram) ${ }^{11}$ e como eu acreditava na liderança de alto nivel, em reescrever livros, testes, materiais

8 O Autor refere-se ao Prof. Dr. Antônio Teixeira Júnior, Professor Aposentado do Instituto de Física da USP.

9 Refere-se à Editora Abril Cultural.

10 Massachusetts Institute of Technology.

$11 \mathrm{O}$ autor refere-se ao ato de prepotência do Governo Militar que, em 1969, promoveu o afastamento compulsório de algumas dezenas de Professores da Universidade de São Paulo. 
suplementares (filmes e livros) e em criar equipamentos simples e de baixo custo para realizar experiências importantes que permitiam aprender a colher informações e as interpretar. Cada projeto dispunha de cerca de 6 milhões de dólares para o seu preparo e introdução, através de cursos de professores. O de física era o PSSC12. Os de biologia eram o BSCS13, liderados por Bentley Glass, famoso cientista e Presidente da Universidade de Stony Brooks. Havia uma versão bioquímica, uma genética e a terceira ecológica. Havia duas quimicas, uma mais tradicional e outra muito mais revolucionária, esta liderada por Pimentel14, famoso professor de química em Berkeley.

Sem o mesmo volume de recursos (o primeiro projeto financiado pela Fundação Ford no Brasil foi para o IBECC/FUNBEC) e, sobretudo, sem a participação de cientistas de alto nivel, resolvi embarcar em adaptar os projetos norte americanos. Durante algum tempo era convidado para as reuniões de planejamento da National Science Foundation, que centralizava este esforço. Miriam Krasilchik ${ }^{15}$, então uma jovem professora lotada no IBECC, assumiu o projeto de biologia, que se inicou pelo preparo do primeiro livro de ecologia para escola secundária (1963). Em seguida, escolhi a versão azul do BSCS, que se centrava na bioquímica. Deixamos para traz as folhas serriadas e alternadas e outras informações que datavam de séculos, para falar em DNA, mutagênicos, enzimas, ATP. Miriam se tornou uma importante líder e co-autora do projeto norte-americano. A física do PSSC substituiu alavancas e planos inclinados pela dualidade onda/partícula e até relatividade, que era a essência da física descobertas meio século antes! $\mathrm{Na}$

\footnotetext{
$12 \mathrm{O}$ autor refere-se ao Physichal Science Study Committee.

13 Biological Sciences Curriculum Study.

$14 \mathrm{O}$ autor refere-se ao Dr. George C. Pimentel, co-autor do Chem Study.

$15 \mathrm{O}$ autor refere-se à $\operatorname{Prof}^{\mathrm{a}} \mathrm{Dr}^{\mathrm{a}}$ Miriam Krasilchik, da Faculdade de Educação da Universidade de São Paulo e sua atual diretora.
} 
química fomos buscar o Prof. Giesbrecht ${ }^{16}$, que ficou com o Chem Study, enquanto ensaiávamos com o Prof. Weiss ${ }^{17}$ (do ITA) o CBA, abandonando a noção de que seria possivel descobrir o que era um composto, com borbulhando um pouco de gás sulfidrico... introduzindo conceitos como entropia, ligações covalentes e ressonância. Estes projetos tornaram-se os currículos básicos para o preparo dos exames do CESCEM, cujos testes foram elaborados por Teixeira, Miriam e Giesbrecht. Os livros deram origem à Editora da Universidade de Brasília e o livro de Biologia vendeu 2 milhões de exemplares.

O impacto desta interação pode ser detectada até hoje, pelo aparecimento nos vestibulares (e nos livros de ciências) de DNA, ATP, entropia, radioatividade, dualidade...palavras antes reservadas a uns poucos que entravam para os cursos superiores de Ciências de poucas Universidades (a fisica da Poli ainda pensava em experiências com resistências de "pasteleiro" e demonstrações usadas há pelo menos um século).

Outra implicação dos exames em larga escala introduzidos pela Fundação Carlos Chagas ocorreu na minha passagem pela Secretaria da Educação, junto com o Prof. Ulhoa Cintra. Nossa Constituição dizia que o ensino deveria ser público e gratuito até a idade de 14 anos. O curso primário durava 4 anos, quando o aluno fazia um exame de admissão ao ginásio. Este exame era individual para cada ginásio e tinha por conseqüência negar a cerca de $50 \%$ dos candidatos a continuidade de sua educação. Resolvemos centralizar o exame de admissão, que tinha que ser oferecido em todo os Municípios. Usamos a Fundação Carlos Chagas para preparar provas e identificar os alunos que poderiam

16 O Autor refere-se ao Prof. Dr. Ernesto Giesbrecht, atualmente Professor Aposentado do Departamento de Química, da Universidade de São Paulo.

17 O Autor refere-se ao Prof. Dr. Karl Herman Weiss, então professor do Instituto Tecnológico de Aeronáutica (ITA), que conheceu o Chemical Bound Approach (CBA) durante uma visita aos Estados Unidos. 
cursar o ginásio. Escolhemos 300.0000 crianças. No ano anterior o Estado tinha oferecido 100.000 vagas. O Governo estava preparado para tomar as medidas necessárias em 3 meses, mas descobrimos que havia classes e carteiras para quase todos. Cumprimos a Constituição e preparamos um onda, que, anos mais tarde, bateu nas Universidade, aumentando o número de candidatos. Eu estava consciente de que o nível cairia no primeiro momento, mas projetava um esforço baseado na experiência da FUNBEC, que retreinou um milhar de professores pelo Brasil afora e os lideres para a inovação em todo o continente. Veio a revolução ${ }^{18}$ e tudo se perdeu.

Os esforços de inovação começaram com investimentos modestos da Fundação Rockefeller e depois da Fundação Ford ao IBECC. A Ford também aceitou meu pedido para a Fundação Carlos Chagas, o que permitiu comprar as primeiras maquinas automática que corrigiam os testes, somavam os pontos e faziam as análises (hoje totalmente obsoletas) e dar bolsas de estudos para formar especialistas em testes de pesquisas educacionais, semente dos programas que Ribeiro Neto ${ }^{19}$ expandiu nos anos 70, transformando a Fundação Carlos Chagas num centro de pesquisas educacionais de alto nivel.

Encontrei a idéia de inovar quando regressei ao País (1979). Os esforços que até então tinham orçamentos modestos, recebeu dentro do projeto PADCT, com um empréstimo do Banco Mundial, cerca de 70 milhões de dólares. Todavia, seus executores não tinham o discernimento de separar o que era transitório para quebrar a inércia das escolas, da velha Lei de Bases e Diretrizes que fazia com que todos os livros,

18 Refere-se ao movimento militar de abril de 1964.

19 O Autor refere-se ao Prof. Dr. Adolfo Ribeiro Netto, então professor da Faculdade de Medicina Veterinária da Universidade de São Paulo, e Diretor-Presidente da Fundação Carlos Chagas (1969-1986). 
independentemente do autor, fossem iguais, da falta de interesse dos professores e, sobretudo, da Universidade que deveria liderar, como o fez nos anos 60, a inovação. As feiras de ciência que iniciei para atrair escolas para introduzir experiências com material simples, foram estimuladas e tornaram-se uma festa de cartolinas e isopores, sem qualquer experiência de fato. A liderança do mais alto nivel para inovar foi substituida por volumosos auxílios a professores de escola média para inovar, quando mal sabiam o que era Ciência e para onde esta caminhava. Deturpou-se a idéia, criando o mito que cada professor em sua escola é um inovador de conteúdo e filosofia do ensino, deixando a divida dos 70 milhões de dólares a pagar.

$O$ erro se perpetua agora, em que professores despreparados, sem qualquer atividade cientifica de peso, escrevem ridículos "parâmetros" que outros professores despreparados usariam como guias para inovar!

Nada é permanente. O processo precisa ser redescoberto.... Voltaram as provas descritivas, mas lentamente descobriram os testes de escolha múltipla. Centralizaram os vestibulares por Universidade, mas estão redescobrindo o vestibular comum a várias Universidades....

Em 1967, estávamos tentando inovar o ensino médico, criando na Cidade Universitária o Curso Experimental de Medicina, que teve um imediato impacto, facilmente mensurável quando a primeira opção no vestibular unificado passou do curso tradicional de Pinheiros para o curso experimental, improvisada e modestamente instalado na Campus. Obviamente, havia cometido um pecado mortal contra a vestuta Casa de Arnaldo $^{20}$. O curso foi extinto e eu aposentado. O modelo do curso experimental, que permite intra-muros a Universidade testar novas formas de curso superior, de

20 O Autor refere-se à Faculdade de Medicina da Universidade de São Paulo. 
novo teve que ser redescoberto (como o curso de Ciências moleculares para formar os cientistas preparados para o avanço da ciência com a total interdisciplinaridade).

Ao contar minha visão da história que nasceu nos porões da Faculdade de Medicina e que ocupa edificios do porte do da Fundação Carlos Chagas e da FUVEST, quero enfatizar que as aventuras educacionais dos anos 60 foram mais importantes do que a mecânica dos vestibulares que permanece. Foi com satisfação que revi como a Fundação Carlos Chagas encontra canais para continuar a contribuir para a Sociedade, sem se tornar apenas o provedor de serviços de seleção ${ }^{21}$.

${ }^{21}$ As notas ao artigo, sem revisão do Autor, foram escritas pelo Editor Responsável de Estudos em Avaliação Educacional e Pesquisador Sênior do Departamento de Pesquisas Educacionais, da Fundação Carlos Chagas, Heraldo Marelim Vianna, que viveu os "tempos heróicos" da instituição referida no presente artigo. 